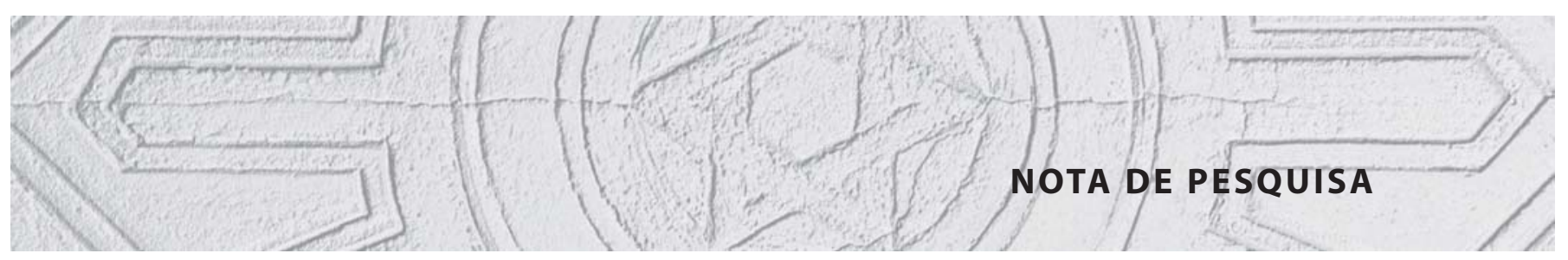

\title{
Antônio Gonçalves Gomide: uma semiologia das doenças nervosas no Brasil*
}

\author{
Antônio Gonçalves Gomide: a semiotics of \\ nervous illnesses in Brazil
}

\author{
Simone Santos de \\ Almeida Silva \\ Doutoranda do Programa de Pós- \\ graduação em História das Ciências \\ e da Saúde/Casa de Oswaldo Cruz/ \\ Fundação Oswaldo Cruz \\ Rua Professor João Lima, 290 \\ 36050-465 - Juiz de Fora - \\ MG - Brasil \\ si33santos@yahoo.com.br
}

SILVA, Simone Santos de Almeida. Antônio Gonçalves Gomide: uma semiologia das doenças nervosas no Brasil. História, Ciências, Saúde Manguinhos, Rio de Janeiro, v.17, supl.2, dez. 2010, p.515-525.

Resumo

Analisa o parecer médico de Antônio Gonçalves Gomide, publicado em 1814. Trata-se de análise crítica realizada pelo médico, a fim de compreender as manifestações de uma beata, Germana Maria da Purificação, que viveu em Minas Gerais, entre os séculos XVIII e XIX. No texto o médico se contrapõe a um exame realizado por dois cirurgiões que declararam o estado da beata como sobrenatural. A intenção é analisar o parecer situando a concepção da patologia da beata para destacar a importância do documento na compreensão da constituição dos saberes médicos no Brasil. Procura-se ressaltar o fato de o texto ter sido um dos primeiros publicados sobre a medicina mental, podendo ser considerado um dos escritos fundadores dessa medicina que se inaugurava no Brasil no século XIX.

Palavras-chave: parecer médico; catalepsia; Antônio Gomide (c.1770-1835); medicina mental; Brasil.

\section{Abstract}

In 1814, physician Antônio Gonçalves Gomide published a medical report in which he offered a critical analysis of the manifestations of a beata (holy woman), Germana Maria da Purificação, who lived in Minas Gerais between the eighteenth and nineteenth centuries. The doctor disagreed with the examination performed by two surgeons, who declared that the state of the beata was "supernatural." The present article analyzes the doctor's report and situates his view of the holy woman's pathology. The text was one of the first ever published on mental medicine and as such stands both as one of the foundational writings of a field that emerged in Brazil in the nineteenth century and also as a valuable source in understanding the formation of medical knowledge in this country.

Keywords: medical report; catalepsy; Antônio Gomide (c.1770-1835); mental medicine; Brazil. 
$\mathrm{E}$ m 1814 o médico Antônio Gonçalves Gomide (c.1770-1835) publicou um parecer médico sobre as manifestações místicas/patológicas de uma beata, irmã Germana Maria da Purificação, que viveu em Minas Gerais entre os séculos XVIII e XIX. ${ }^{1}$

O primeiro contato que tive com o parecer médico do doutor Gomide ocorreu ainda no mestrado, quando eu pesquisava a vida da irmã Germana a fim de delinear aspectos da religiosidade feminina no Brasil. A leitura do diagnóstico escrito pelo médico me conduziu ao que se tornaria o objeto central da minha investigação: a constituição dos saberes médicos em formação, em especial aqueles em torno da medicina mental, entre os séculos XVIII e XIX; o discurso médico-científico luso-brasileiro, e a contribuição de Impugnação analítica de Antônio Gonçalves Gomide para o reforço das concepções das doenças como um processo natural. Na leitura desse documento busco desviar o foco da análise sobre as beatas, objeto pesquisado anteriormente, para concentrar esforços no parecer de Gomide.

A intenção não é oferecer um posicionamento acerca do diagnóstico, mas sim analisar o universo da ciência e da medicina apresentado pelo médico. No momento estou interessada especificamente em situar a compreensão do médico, naquele momento, a respeito da patologia da beata, concebida por ele como catalepsia. Busco estabelecer como Gomide compreendia a catalepsia, a histeria e demais doenças nervosas, à luz dos seus estudos da literatura estrangeira, sobretudo inglesa, em fins do século XVIII. Pontuando as idéias médico-filosóficas delineadas no seu parecer, é possível situar a importância de Impugnação analítica para a constituição dos saberes médicos acerca das doenças nervosas, no Brasil, no período entre os séculos XVIII e XIX.

\section{Irmã Germana e seus êxtases: as controvérsias médicas em Impugnação analítica}

Nascida em 1782, Germana sofreu desde a infância daquilo que foi considerado, por alguns, 'afecções histéricas' e convulsões que a impossibilitavam de andar. Desejando viver recolhida, numa vida de oração e penitência, conseguiu autorização para morar junto ao seu confessor na Serra da Piedade, um local que, desde a fundação de sua primeira capela, fora rodeado de relatos de milagres e experiências místicas e no qual estavam presentes os beatos (Saint-Hilaire, 1974, p.68).

Segundo o naturalista Auguste de Saint-Hilaire (1779-1853), que também esteve na Serra da Piedade, ali irmã Germana "entrou numa espécie de êxtase, seus braços endureceram e estenderam-se em forma de cruz; e ela se manteve nessa atitude durante 48 horas sem fazer um movimento, sem proferir uma palavra, sem tomar qualquer alimento" (SaintHilaire, 1974, p.68). Ainda conforme o naturalista, Germana mantinha-se imóvel, seu pulso lento, sua respiração ligeira, seu corpo rígido. Ele declarou ter experimentado flexionar os braços da beata o que foi impossível, devido à tensão muscular que apresentava o corpo.

Tais manifestações, consideradas místicas por uns e patológicas por outros, motivaram controvérsias marcantes na história de vida da beata. Germana tornou-se uma santa diante do imaginário religioso popular daquela localidade. Mas se a beata foi adorada pelos fiéis, também foi perseguida por parte daqueles que a qualificavam como uma figura controversa e deslegitimavam a santidade e a veracidade de seus êxtases. Isso provocou uma longa discussão entre estudiosos, especialmente no campo das ciências médicas. 
Impugnação analítica foi um dos propulsores dessas controvérsias acerca das manifestações da irmã. A redação desse parecer médico ocorreu a partir da rejeição do doutor Gomide ao exame realizado anteriormente por dois cirurgiões, Antônio Pedro de Sousa e Manuel Quintão da Silva. Esses cirurgiões embora admitindo que os sintomas fossem característicos de uma enfermidade rara, reconheceram o caráter sobrenatural das experiências extáticas da beata, declarando que a admiração pela Paixão de Cristo não faz ninguém doente, mas sim santo.

Esse exame, de acordo com o doutor Gomide (1814), fez com que um grande número de romeiros se dirigisse ao local a fim de reverenciar a beata. Contra o exame dos cirurgiões, que defenderam os êxtases da beata como sinais de santidade, e a favor da ciência e da verdade é que o médico produziu Impugnação analítica. Seu objetivo era demonstrar que, no caso das manifestações da beata, "uma semiologia razoável nada mais acharia que doença" (p.6). Segundo o doutor Gomide, os êxtases não passavam de achaques e nada tinham de sobrenatural.

Antes de passarmos à controvérsia propriamente dita, é importante conhecer o autor de Impugnação analítica, aproximar-se da sua trajetória, na tentativa de compreender os motivos que o levaram a elaboração de um diagnóstico médico sobre a irmã Germana, rebatendo os cirurgiões que a declararam santa.

\section{O médico}

Antônio Gonçalves Gomide, filho de 'mineiros distintos', nasceu em Minas Gerais, onde fez seus estudos preparatórios. Foi para Portugal, conforme o costume das famílias mais ricas de enviarem seus filhos para os estudos universitários na Europa. Formou-se em direito em Coimbra, onde tomou o grau de doutor, e também estudou medicina na Universidade de Edimburgo, na Escócia (Macedo, 1880, p.83; Dornas Filho, 1949, p.87).

Segundo a documentação consultada, o médico retornou de Portugal em junho de 1792, provavelmente após concluir seus estudos em Coimbra, e desembarcou no Rio de Janeiro em setembro do mesmo ano, seguindo em direção a Minas Gerais. Os documentos informam-nos ainda que o doutor Gomide passou os primeiros anos após seu retorno da Europa entre as cidades de Caeté e Sabará. Assumiu em 1792 o cargo de professor de Gramática Latina; por volta do ano de 1801, foi vereador da Câmara de Caeté, então Vila Nova da Rainha. Em seguida, assumiu o cargo de capitão da ordenança e de tabelião, circulando entre Minas Gerais e Rio de Janeiro até pelo menos o ano de 1808, quando foi eleito procurador por Minas Gerais para a cerimônia real do beija-mão.

Doutor Gomide permaneceu entre um cargo e outro sempre em busca de títulos, como o Hábito da Ordem de Santiago e o almejado Hábito de Cristo, que foi obtido em 1806. Não se sabe ao certo a trajetória do médico no período entre 1808, quando participou da cerimônia de boas-vindas ao rei de Portugal, e 1814, data da publicação de Impugnação analítica. No entanto podemos concluir que ele era uma figura influente no cenário político e social nesses anos, pois em 1823 foi eleito deputado por Minas Gerais e, mais tarde, senador do Império (Macedo, 1880, p.83).

No que diz respeito à atuação política de Antônio Gonçalves Gomide, destacam-se suas ações nas comissões de Saúde Pública e Instrução Pública, entre outras. Nesta última comissão, 
aliás, esforçou-se para sintonizar a Colônia com o ambiente da Ilustração. Segundo o doutor Gomide, "a instrução pública e a difusão das luzes é o primeiro dever dos governos. Todas as virtudes físicas e morais das nações se desenvolvem na razão direta de suas luzes" (Brasil, 1823). Gomide, como senador, dedicou-se à questão dos problemas educacionais da nação, propondo a criação de uma universidade em Minas Gerais. Já na Comissão de Saúde Pública foi adepto da proposta de reestruturação do ensino da medicina e demais ramos das ciências naturais, apoiando os projetos da comissão encarregada de um plano de estudos. Segundo o médico esse plano era "o melhor que se pode conceber no estado atual da ciência; tudo que há de melhor nos cursos de medicina na Europa, tanto na Alemanha, como na Itália e França, foi coligido pelos nobres redatores do projeto" (Brasil, 1832).

A valorização da ciência produzida na Europa, seguida do desejo de produzir algo semelhante na Colônia, demonstra que médico mantinha-se sintonizado com as ideias européias e estava interessado na difusão e aplicação delas no Brasil (Kury, 2004, p.109; Dantes, 1988, p.265).

Impugnação analítica, escrito em 1814, oferece-nos justamente uma mostra desse seu antigo interesse de conversão e aplicação das práticas científicas empreendidas na França, Inglaterra e nos demais países europeus.

\section{Impugnação analítica}

O texto, publicado pela Imprensa Régia, foi organizado em três partes, sendo a primeira introdutória, em que o doutor Gomide apresenta-se ao físico mor do Reino, Manoel V. da Silva, reverenciando seus méritos e conhecimentos médicos. Acompanha a introdução desse trabalho um pedido de anonimato para a autoria da publicação, pois o médico alega temer "maquinações dos seus fautores, cujo ressentimento crescia a proporção do triunfo da verdade" (Gomide, 1814, p.6).

Na parte seguinte de Impugnação analítica, intitulada "Advertência", o doutor Gomide (1814) apresenta a beata, fala sobre a peregrinação em torno dela e da admiração dos fiéis em torno dos fenômenos. O médico declara nessa advertência que seu objetivo é contrariar o exame dos clínicos por meio de uma semiologia, limitando-se "às citações de autoridades que se poderão consultar" (p.10). O médico declara ainda que sua impugnação ao exame dos clínicos se justifica, pois é dever do "filósofo achar, e promulgar a verdade" (p.11).

Na terceira parte de Impugnação analítica, o médico inclui o exame dos clínicos em que se verifica a defesa das manifestações da irmã Germana como fenômenos sobrenaturais. ${ }^{2} \mathrm{~A}$ quarta parte o doutor Gomide inicia com uma série de críticas ao exame dos clínicos, acompanhadas de adjetivos que desqualificam e satirizam o diagnóstico oferecido por eles. Nessa parte do parecer, também se esforça para apresentar seus argumentos de maneira erudita, apoiado em um discurso de autoridade que enfileira citações variadas de médicos e cientistas europeus.

Doutor Gomide $(1814$, p.13, 16) refere-se aos cirurgiões que atestaram o estado sobrenatural da beata como homens de "espíritos fracos", vítimas de um juízo extraviado e autores de "paralogismos ridículos e pueris". Os fenômenos da irmã Germana, segundo o médico, 
eram resultado do estado patológico da beata, frutos das diferentes anomalias da "ação nervosa", que levaram pessoas ignorantes a considerá-la influenciada por Deus ou pelo diabo. A intenção do doutor Gomide era dar ênfase aos êxtases da beata como parte de um quadro de "catalepsia convulsiva" uma doença epiléptica.

Segundo o doutor Gomide, os cirurgiões eram supersticiosos e tinham como obrigação planejar um tratamento para a paciente, que, abandonada, poderia ficar louca ou apoplética. Dirigiu-se então aos próprios clínicos afirmando:

Vós fazeis ultraje à religião, e à Igreja quando a questão por terminada resolveis, e decidis tão pronta e categoricamente de negócio, que ela examina, e analisa com a mais profunda escavação. Os que duvidam da vossa santa, porque eles conhecem a doença, não são incrédulos, são prudentes e ortodoxos, como são supersticiosos e néscios, os que querem por força canonizar.

Não se duvida da realidade, mas era do vosso dever indagar previamente, e com a delicadeza, tino e sagacidade se a doença era, ou não fingida tanto pelos inumeráveis exemplos de falsificações deste gênero, como pela ponderável tese do doutor Cullen, de que a catalepsia é sempre simulada.

Porém vós não viestes observar uma cataléptica, vínheis de casa prevenidos a ver uma Santa. O espírito humano tem aprendido à sua custa a discernir o sólido do frívolo, o verdadeiro do falso, o possível do impossível. Canonizar as santas pertence exclusivamente à Igreja, e ao filósofo compete descobrir e promulgar a verdade natural. A credulidade da multidão ignorante chancelada pelo vosso galimatia, além da consagração do erro, danifica diretamente a sociedade, privando-a por cálculo bem moderado de um milhão de serviços na sôfrega concorrência de romeiros, que empregados em qualquer trabalho produtivo teriam aumentado sensivelmente a riqueza da nação (Gomide, 1814, p.26-27).

O parecer médico do doutor Gomide, ao refutar o exame dos clínicos que analisaram as manifestações da beata, dá inicio a uma controvérsia que foi muito além do fato de serem sobrenaturais ou patológicos os êxtases da mulher. O interessante nessa discussão são as polêmicas suscitadas pelo parecer e o modo, segundo o doutor Gomide, de se fazer um correto diagnóstico médico, baseado na leitura dos livros e periódicos médicos modernos, produzidos na Inglaterra, França e Itália.

Na maior parte das fontes consultadas, Impugnação analítica foi citado como um trabalho importante. Saint-Hilaire (1974, p.61) a considerou como uma obra "cheia de ciência e de lógica". O redator da Gazeta do Rio de Janeiro, na edição de 18 de dezembro de 1814, anunciando o livreto do doutor Gomide para venda, declarou que o discurso do médico foi merecedor da atenção de ilustrados professores de medicina (Oliveira, 1997, p.53). Após mais de um século, opiniões diversas sobre o médico e seu parecer constavam ainda em jornais e revistas. Em edição do Jornal do Commercio de 1942, por exemplo, Impugnação analítica foi apresentado como um "trabalho sério e consciencioso que merece divulgação pelas idéias que expõem, muitas das quais ainda hoje, de palpitante atualidade social e científica". Segundo o jornalista João Dornas Filho $(1949$, p.88), doutor Gomide foi um grande conhecedor da ciência e sua avaliação "destrói com vantagens a tese dos seus colegas de profissão".

Em 1958, em artigo publicado no jornal O Estado de Minas, Augusto de Lima Junior (1889-1970) sentia ainda a necessidade de questionar Impugnação analítica, realizado pelo 
doutor Gomide havia mais de cem anos, justificando suas críticas ao fato de o médico não ter visitado a Serra da Piedade para realizar pessoalmente o exame na paciente. De maneira surpreendente, alguns anos depois do artigo de Augusto de Lima Junior, o médico psiquiatra Clóvis de Faria Alvim (1920-1979) respondeu às críticas daquele declarando que o fato de o doutor Gomide não ter examinado a beata não invalidava o documento, já que, segundo o psiquiatra, seria "perfeitamente dispensável o exame quando se trata de dar parecer sobre laudo médico já existente" (Alvim, 1962, p.239).

Clóvis Alvim (1962) considerou a avaliação do doutor Gomide um dos primeiros estudos sobre psiquiatria no Brasil e declarou que o médico foi grande conhecedor de história, medicina e psiquiatria. Segundo Alvim, Impugnação analítica representou um importante documento para a história da psiquiatria brasileira; foi "uma peça minuciosa, exaustiva, amplamente documentada. É algo de extraordinário que existisse em Minas naquela época, em local tão deserto e desprovido de recursos, homem de tamanha cultura e despido de preconceitos, para afrontar corajosamente a crendice comum" (p.241).

\section{As idéias filosófico-científicas: o centro do debate}

Os argumentos desenvolvidos pelo doutor Gomide em Impugnação analítica, ao apresentar o "correto diagnóstico" sobre a beata, demonstram a sintonia da sua formação teórica com os referenciais europeus daquele momento, no âmbito dos estudos psiquiátricos, bem como sua adesão a princípios que acabaram por conformar a psiquiatria brasileira, que sequer havia aparecido no período de modo sistematizado. ${ }^{3}$ Ao longo do texto, o médico apresenta várias referências acerca dos autores mais expressivos e dos periódicos mais indicados produzidos na Europa sobre a temática, como Boerhaave (1668-1738), Bichat (1771-1802), Cabanis (1757-1808), Cullen (1710-1790) e Duncan (1744-1828).

Doutor Gomide apresentou-se, portanto, como um intelectual que gostava de se exibir em plano de igualdade com os pesquisadores europeus, mantendo-se inserido nas grandes questões da época. Ele buscava se situar diante dos debates científicos, revelando nos seus discursos uma postura similar aos demais homens de ciência de seu período.

Traduzir, aprender e aplicar os saberes produzidos na Europa, sobretudo no caso dos saberes médicos, era prática comum no Brasil do início do século XIX. Foi fruto de uma necessidade de construir um saber local, parte de um processo de legitimação das ciências, presente na imprensa e nas instituições criadas durante o período joanino (Kury, 2008, p.4). Confirme destaca Maria Odila S. Dias (1968), os estudiosos brasileiros, na virada do século XVIII para o XIX, estavam preocupados em integrar o Brasil na cultura ocidental e pareciam "a cada página lembrar e afirmar a sua participação na comunidade de sábios e ilustrados do seu tempo" (p.134).

Os argumentos do doutor Gomide em defesa do caráter patológico das manifestações da beata são cuidadosamente apresentados e acompanhados de citações de trabalhos dos cientistas reconhecidos, produzidos nos centros de saberes da época, como as universidades de Edimburgo e Montpellier ou a Academia de Ciências de Paris.

Em Impugnação analítica, o doutor Gomide cita casos de outras mulheres portadoras de anomalias nervosas, de acidentes epilépticos e vaporosas, diagnosticando a doença da 
irmã Germana como uma "catalepsia convulsiva", "um rendimento da epilepsia". ${ }^{4}$ Ele se baseia, para o estabelecimento desse diagnóstico, em nomes como o do médico francês Philippe Pinel (1745-1826), que destacou o enfoque da clínica sobre a psiquiatria, e em William Cullen, médico e professor da Universidade de Edimburgo que estudou as enfermidades nervosas sem febre, para analisar a possibilidade de simulação por parte da beata (Gomide, 1814; Cullen, 1782). O médico menciona ainda as experiências da anorexia e da bulimia vivenciadas por algumas mulheres, com base nos escritos de médicos e filósofos como Erasmus Darwin (1794-1796).

Doutor Gomide cita outros nomes das ciências médicas, como Sydenham (1624-1689), Crichton (1763-1856), Tissot (1728-1797), Cabanis (1757-1808) e Whytt (1714-1766), cuja leitura recomendava aos cirurgiões para que compreendessem o estado patológico da beata. Além desses, Bacon (1561-1626), Locke (1632-1704), Newton (1643-1726), Shakespeare (15641616), Pope (1688-1744), Chiarugi (1759-1820), Boerhaave (1668-1738) e outros são indicados também como referência bibliográfica para o posterior estudo.

Para o doutor Gomide, a beata, por sofrer de catalepsia, permanecia num estado de total irritabilidade e sensibilidade nervosa, o que a deixava suscetível a variados fenômenos decorrentes dessa enfermidade, como histeria, paralisia, movimentos convulsivos e rigidez muscular.

Boerhaave e Van Switen (1700-1772), ambos mencionados em Impugnação analítica, estudaram as sensibilidades das mulheres 'doentes dos nervos', sobretudo os casos de manifestações histéricas. Segundo Van Swieten, angústias, espasmos, dores facilmente acometiam as mulheres que se entregavam demasiadamente aos estudos e à meditação; tais moléstias seriam frutos da sensibilidade das fibras dessas mulheres de constituição fraca (Foucault, 2007, p.282)

Conforme verificamos, o ilustrado médico Antônio Gonçalves Gomide estava bem amparado na literatura médica; citações e referências a sociedades científicas e periódicos o apoiavam em seus objetivos e nos oferecem uma boa noção da orientação científica que ele buscava. No entanto não é possível afirmar que ele se manteve alinhado a apenas uma ou outra orientação filosófica, mesmo porque a ausência de unidade no pensamento médico-científico europeu também se fazia presente entre os médicos luso-brasileiros. No caso dos acadêmicos da Faculdade de Medicina do Rio de Janeiro, percebe-se que possuíam diferentes orientações teóricas no período da ilustração luso-brasileira. Dialogavam com a Nosografia de Pinel, ao mesmo tempo com os trabalhos do médico francês Broussais, opositor das classificações pinelianas das doenças, e também se apoiavam nos trabalhos do médico inglês John Brown (1735-1788), cujo estudo sobre excitabilidade dos órgãos foi recusado em Montpellier e em Paris (Ferreira, 1996, p.44; Kury, 2002, p.3).

No caso do doutor Gomide é possível afirmar, a partir das suas citações, que se orientava nas escolas médicas francesas e inglesas, com destaque para Edimburgo, um centro de saber referencial para toda Europa no século XVIII (Chitnis, 1972).

A partir daí pode-se perceber que ele compreendia a medicina com base no conhecimento científico e na ciência experimental, em oposição à medicina prática dos cirurgiões. As concepções médicas do doutor Gomide estavam de acordo com as idéias médicas iluministas, que postulavam que, para assegurar o progresso das luzes, a medicina deveria se estruturar 
de maneira mais científica, com base na observação e experimentação, sendo o conhecimento prático tão ou mais significativo do que o teórico (Porter, 1999, p.385)

Doutor Gomide (1814) se mostra, em Impugnação analítica, um defensor desse discurso iluminista. Suas palavras condenam a atitude dos clínicos, que "na sua prática, acima dos autores", não reconheceram na literatura os inúmeros casos semelhantes ao da beata (p.13). Ele sinaliza a legitimidade dos novos médicos em oposição aos cirurgiões, pois sua autoridade e seu conhecimento baseado no método da observação e experimentação capacitavam-no a melhor identificar os sintomas das doenças. E denuncia ainda os cirurgiões que, defendendo o estado sobrenatural dos fenômenos da beata, não deram ênfase à observação do fenômeno, o que os teria desviado da verdade. Segundo o doutor Gomide (p.13), “o hábito de observar refreia a imaginação; e a experiência, ou própria, ou de autoridade, destrói os erros".

O doutor Gomide (1814, p.12) comenta ainda que os sintomas da beata "se desenvolvem materialmente das modificações do princípio vital", o que aponta a possibilidade de o médico ter sido influenciado pelas correntes animistas e vitalistas na Europa no século XVIII.

As idéias animistas foram defendidas por Boussier de Sauvages (1706-1767), que percebia a alma como causa única que forma, conserva e repara os órgãos. Esse médico foi adepto das idéias de Sthal, para quem a matéria viva é caracterizada pelo princípio chamado anima, que provoca os movimentos responsáveis pela vida. Já as idéias vitalistas oriundas do animismo defendiam a existência de uma força vital que se encontraria na origem da sensação, do movimento e da vida. Tais ideias apresentavam uma nova concepção da condição humana. Entre as escolas vitalistas do século XVIII merecem destaque a de Montpellier, em especial os nomes de Théophole de Bourdeu (1722-1776) e Paul Joseph Barthez (1734-1806), e a de Edimburgo, com destaque para os citados Cullen e Brown. Também se destacaram as escolas vitalistas alemã e italiana (Entralgo, 1954; Williams, 1994; Porter, 1999).

Como as ideias médico-filosóficas de Antônio Gonçalves Gomide foram concebidas com apoio numa infinidade de estudos europeus do período, resta saber por que o médico se preocupou em articular tantos trabalhos e autores. Talvez estivesse preocupado em convencer seus leitores da origem natural dos fenômenos da irmã Germana e do caráter patológico de suas manifestações. Talvez seu objetivo fosse apenas demonstrar erudição e conhecimentos científicos acerca das doenças nervosas. O desafio a que me proponho na pesquisa é mapear a literatura apresentada no documento, a fim de circunscrever suas orientações filosóficas e situar sua trajetória, obtendo, a partir dele, mais clareza sobre a medicina mental no Brasil entre os séculos XVIII e XIX.

\section{Considerações finais}

O parecer médico do doutor Antônio Gonçalves Gomide suscita questões sobre a institucionalização da medicina científica entre os séculos XVIII e XIX, a atuação dos práticos e a introdução de um saber científico e moderno acerca das 'anomalias da ação nervosa' no Brasil.

Analisar as fontes, investigar o objeto, deslocando o olhar sobre o tema, antes centrado nas beatas, para privilegiar o campo da medicina foi um importante passo. 
No caso do doutor Gomide percebe-se sua preocupação em situar-se como um portavoz da medicina científica, apoiado nas teorias das modernas escolas estrangeiras, a fim de rebater com autoridade a opinião dos cirurgiões. Apesar de o médico ter buscado circunscrever e nomear a patologia da irmã Germana - a catalepsia -, discorrendo sobre os sintomas da sua patologia, verifica-se que acabou fazendo uma miscelânea de idéias.

Seu parecer, recheado de variadas citações e casos clínicos, seguidos das descrições do que acontecia com a beata, embora se apresente como um rico documento para pesquisa, apresenta uma argumentação teórica confusa, o que dificulta o trabalho de mapeamento das idéias médico-filosóficas do médico no contexto da época.

Apesar das dificuldades, é possivel constatar que seu discurso estava alinhado com o que havia de mais moderno nas práticas e teorias científicas do período. A pesquisa mostra claramente que havia uma sintonia do médico com os saberes produzidos nos grandes centros universitários da época, especialmente em Edimburgo. Tal percepção reforça as declarações encontradas nas fontes sobre a presença do doutor Gomide na universidade escocesa, ou pelo menos indicam que ele se mantinha atualizado com os estudos praticados nessa e outras instituições da época.

Para além das conclusões do doutor Gomide no diagnóstico, o que importa é que sua maior contribuição foi Impugnação analítica. Um texto que, conforme mostra a pesquisa que venho realizando, pode ser considerado pioneiro sobre os estudos das doenças mentais no Brasil no início do século XIX e que contribui não só para a ciência médico-filosófica do período, como também para a historiografia atual.

\section{NOTAS}

*O presente trabalho é resultado da pesquisa que desenvolvo para minha tese de doutoramento no Programa de Pós-graduação em História das Ciências e da Saúde da Casa de Oswaldo Cruz/Fiocruz.

${ }^{1} \mathrm{O}$ parecer médico escrito pelo médico Antônio Gonçalves Gomide é intitulado Impugnação analítica do exame feito pelos clínicos Antônio Pedro de Sousa e Manuel Quintão da Silva em uma rapariga que julgaram santa na Capela de Nossa Senhora da Piedade da Serra, próxima à Vila Nova da Rainha do Caeté. Comarca do Sabará, oferecida ao ilustríssimo Senhor Doutor Manoel Vieira da Silva Primeiro Médico da Comarca de Sua Alteza Real, e de seu Conselho, Fidalgo da Casa Real, Físico Mor do Reino, Estados e Domínios Ultramarinos, Comendador das Ordens de Cristo e da Torre Espada e Provedor Mor da Saúde. Para facilitar a leitura deste texto, doravante refiro-me a ele como Impugnação analítica.

2 Segundo o naturalista Auguste de Saint-Hilaire, cópias manuscritas do diagnóstico dos cirurgiões teriam circulado na região, no entanto localizei esse exame somente no parecer do doutor Gomide.

${ }^{3}$ Segundo a historiografia os primeiros sinais da institucionalização da psiquiatria no Brasil surgiram após 1830, com a criação da Sociedade de Medicina e Cirurgia do Rio de Janeiro, sendo que tradicionalmente se considera que o primeiro texto escrito sobre a psiquiatria teria sido publicado em 1837 pelo doutor Antônio L.M. Peixoto. Ainda segundo as análises historiográficas correntes, o marco desse processo de fortalecimento da atividade psiquiátrica no Brasil foi a fundação do Hospício de Pedro II, em 1852 (cf. Machado et al., 1978; Engel, 2001, Teixeira, 1997). O documento do doutor Antônio G. Gomide nos mostra que esses marcos em torno dos estudos psiquiátricos no Brasil não são tão incisivos.

${ }^{4}$ Conforme o dicionário de Moraes e Silva (1956, p.1012), Catalepsia é uma perturbação da psicomotricidade, que consiste numa particular imobilidade e inércia do todo o corpo, com prolongada conservação das atitudes espontânea ou passivamente tomadas. Na edição de 1813 do mesmo dicionário, o termo cataléptico refere-se a pessoa sonolenta, com convulsão tônica de todo o corpo, o que conserva o doente na postura em que tomou esse acidente. 


\section{REFERÊNCIAS}

ALVIM, Clóvis Ferreira.

Um precursor mineiro da psiquiatria brasileira. Revista da Universidade de Minas Gerais, Belo Horizonte, n.12.p.234-250. 1962.

BRASIL.

Anais do Senado Federal - Império, 1832, Livro v.1: Senado, sessões preparatorias, Acta do dia 27 de abril de 1832. Disponível em: http:// www.senado.gov.br/publicacoes/anais/asp/ AP_Apresentacao.asp. Acesso em: 14 jul. 2010. 1832 .

BRASIL.

Congresso. Câmara dos Deputados. Anais da Câmara dos Deputados (1826-1974). Sessão de 5 de julho de 1823. Brasília: Câmara dos Deputados, Coordenação de Publicações. Disponível em: http://imagem.camara.gov.br/ dc_20a.asp?selCodColecaoCsv=C\&Datain $=5 / 7 /$ 1823. Acesso em: 18 jul. 2009. 1823.

CHITNIS, Anand C.

Medical education in Edinburgh, 1790- 1826, and some Victorian social consequences. Disponível em: http://www.ncbi.nlm.nih.gov/pmc/articles/ PMC1081447/pdf/medhist00123-0071.pdf. Acesso em: 14 jul. 2010. 1972.

DANTES Maria Amélia.

Fases da implantação da ciência no Brasil. Quipu, México, v.5, n.2, p.265-275. 1988.

DIAS, Maria Odila Leite da Silva. Aspectos da Ilustração no Brasil. Revista do Instituto Histórico e Geográfico Brasileiro, Rio de Janeiro, n.278. 1968.

DORNAS FILHO, João.

Figuras da província. Belo Horizonte: Movimento Editorial Panorama. (Coleção Vila Rica, 1). 1949.

ENGEL, Magali.

Delírios da razão: médicos, loucos e hospícios. Rio de Janeiro: Editora Fiocruz. 2001.

ENTRALGO, Lain.

História de la medicina: medicina moderna y contemporânea. Lisboa: Editorial Científico Médica. 1954.

FERREIRA, Luiz Otávio.

O nascimento de uma instituição científica: o periódico médico brasileiro na primeira metade do século XIX. Tese (Doutorado em História) Faculdade de Filosofia, Letras e Ciências Humanas, Universidade de São Paulo, São Paulo. 1996.

FOUCAULT, Michael.

História da loucura na Idade Clássica. São Paulo: Perspectiva. 2007.
GOMIDE, Antônio Gonçalves.

Impugnação analítica do exame feito pelos clínicos Antonio Pedro de Sousa e Manuel Quintão da Silva em huma rapariga que julgaram santa na Capela de Nossa Senhora da Piedade da Serra, próxima à Vila Nova da Rainha do Caeté. Rio de Janeiro: Imprensa Régia. 1814.

KURY, Lorelai.

Rio de Janeiro: a cidade e os médicos no período joanino. In: Scott, Ana Silvia Volpi; Fleck, Eliane Deckmann (Org.). A corte no Brasil: população e sociedade no Brasil e em Portugal no início do século XX. São Leopoldo: Oikos; Unisinos. 2008.

KURY, Lorelai.

Homens de ciência no Brasil. História, Ciências, Saúde - Manguinhos, Rio de Janeiro, v.11, supl.1, p.109-29. 2004.

\section{KURY, Lorelai.}

Um médico no Império: Cruz Jobim interpreta a ciência européia. In: 10ํㅡㄹ Encontro Regional de Historia, 2002, Rio de Janeiro. Anais... Rio de Janeiro: Anpuh. Disponível em: http:// www.rj.anpuh.org/resources/rj/Anais/2002/ Comunicacoes/Kury\%20Lorelai.doc. Acesso em: 14 jul. 2010. 2002.

MACEDO, Joaquim Manoel.

Anno Biographico Brazileiro. Supl. Rio de Janeiro: Typographia e Lithographia do Imperial Instituto Artístico. 1880.

MACHADO, Roberto et al.

Danação da norma: a medicina social e constituição da psiquiatria no Brasil. Rio de Janeiro: Graal. 1978.

MORAES E SILVA, Antônio de. Grande dicionário da língua portuguesa. v.9. Lisboa: Editorial Confluência. 1956.

MORAES E SILVA, Antônio de.

Diccionario da lingua portugueza: recopilado dos vocabulários impressos até agora. Lisboa: Typographia Lacerdina. 1813.

OLIVEIRA, José Carlos.

A cultura científica e a Gazeta do Rio de Janeiro. Revista da Sociedade Brasileira de História da Ciência, Rio de Janeiro, n.17. p.29-58. 1997.

PORTER, ROy.

Le dix-huitième siècle. In: Conrad, Neve et al. Histoire de la lute contre la maladie: la tradition médicale occidentale de l'Antiquité à la fin du siècle des Lumières. Paris: Institut Synthélabo pour le progrès de la connaissance. 1999. 
SAINT-HILAIRE, Auguste de.

Viagem pelo distrito dos diamantes e litoral do Brasil. Belo Horizonte: Itatiaia. 1974.
WILLIAMS, Elizabeth Ann.

Hysteria and the court physician in

Enlightenment France. Eighteenth-Century

Studies, Baltimore, v.35, n.2. 2002.

\section{$\rightarrow \rightarrow \rightarrow<<<$}




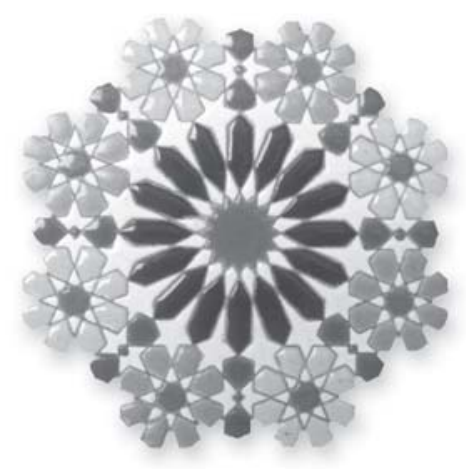

